\title{
Os gêneros discursivos e o ensino/aprendizagem de língua portuguesa no ensino médio
}

\author{
Discursive genres and the teaching/learning of Portuguese \\ in high schools
}

\author{
Sandra Mara Moraes Lima* \\ sandralima605@gmail.com \\ Pontifícia Universidade Católica de São Paulo
}

\begin{abstract}
RESUMO: O trabalho se propõe a discutir o conceito de gênero discursivo veiculado pelo Círculo bakhtiniano, considerando o ensino/aprendizagem de língua materna na educação básica. Toma como pressuposto a teoria de que os gêneros discursivos constituem categorias primordiais para a interação discursiva, uma vez que os gêneros nos são dados como nos é dada a língua materna e que são introduzidos em nossa experiência e em nossa consciência conjuntamente sem que sua estreita correlação seja rompida. A proposta, nesse momento, também, faz uma breve análise dos manuais didáticos do Ensino Médio da rede estadual do estado do Espírito Santo, adotados no triênio de 2012 a 2014, com o objetivo de demonstrar como conceito de gênero discursivo é abordado e aplicado no ensino/aprendizagem de Língua Portuguesa no Ensino Médio nos referidos manuais.
\end{abstract}

PALAVRAS-CHAVE: Gênero discursivo. Ensino/aprendizagem. Língua Materna.

ABSTRACT: This article aims at discussing the concept of discursive genre discussed by the Bakhtin Circle, taking into consideration mother tongue teaching/learning processes in school. We assumed that the discourse genres theory constitutes primary categories for discursive interaction, since genres as well as our mother tongue are given to us and introduced into our experiences and our consciousness without having their tight connexion interrupted. This article also brings a brief analysis of high school textbooks used in public schools from Espírito Santo between 2012 and 2014 in order to demonstrate how the concept of discourse genre is approached and applied in the teaching/learning processes of Portuguese.

KEYWORDS: Discourse genre. Teaching/learning. Mother tongue.

\footnotetext{
* Doutora em Linguística Aplicada e Estudos da Linguagem pela Pontifícia Universidade Católica de São Paulo, com estágio de pós-doutoramento sob supervisão da $\mathrm{Dr}^{\text {a }}$ Beth Brait.
} 


\section{Introdução}

Embora saibamos que a crise que se instaurou na educação brasileira, há muitos anos, levando a certa falência, principalmente no que diz respeito à competência linguística para leitura e escrita, não se deve apenas a aspectos metodológicos e epistemológicos, antes aponta para diversos fatores, o que tem sido grande desafio para educadores e instituições: debelar uma crise cuja causa é multifatorial. No entanto, não há como negar que fatores metodológicos podem favorecer ou prejudicar, estar mais ou menos adequados aos propósitos educacionais. E, em se tratando de leitura e escrita, consideramos que a concepção de língua/linguagem que faça uma abordagem tendo em vista os modos de produção do sentido pode ser mais profícua, pois o processo ensino/aprendizagem fora dessas condições se dá de maneira parcial e frágil. Nesse sentido, a perspectiva filosófica acerca da linguagem trazida por Bakhtin e o Círculo contribue bastante para uma metodologia de ensino de língua materna mais significativa, uma vez que essa concepção procura enfocar a língua em sua essência, ou seja, priorizando a interação discursiva que comporta todas as condições de produção do enunciado, o que é preponderante para a construção dos sentidos.

De acordo com pesquisas anteriores (LIMA, 2010), constatamos, de acordo com Bakhtin/Volochinov, que a sistematização da língua em caráter fragmentário, focalizando seus aspectos formais, desenvolveu-se plenamente no âmbito das línguas mortas, desvinculado de seu processo ideológico. Segundo Bakhtin a reflexão linguística de caráter formal-sistemático foi levada a adotar a mesma sistematização em relação às línguas vivas, a tratar a língua como um objeto pronto e acabado, desconsiderando todo o processo histórico-ideológico, voltando-se para o estudo da enunciação numa perspectiva monológica isolada, isto é, a enunciação fora dos contextos de produção e recepção.

Esse enfoque da língua atravessou a tradição da pesquisa linguística bem como migrou para os programas de ensino de língua, o que parece ter promovido um ensino, em alguns pontos, artificial, uma vez que ao enfocar a língua desvinculada de seu caráter semiótico-ideológico, de suas condições de enunciação e de produção de sentido, promove, algumas vezes, um ensino de língua desprovido de sentido, o que pode levar a uma dificuldade de aprendizagem, de uma 
apropriação deficiente da leitura e da escrita, já que esse enfoque de ensino pode desencadear uma dificuldade do aprendiz em identificar nesse ensino a língua que usa, pois, como afirma Bakhtin, o falante não assimila as formas da língua, mas as condições em que a língua produz sentido para ele.

Em se tratando do ensino de língua portuguesa no Brasil, não é raro ouvirmos alunos, falantes nativos da língua portuguesa em geral, proclamando não saber falar e, sobretudo, não saber escrever português e que o seu idioma é uma língua muito difícil. Isso se dá muito provavelmente, entre outros fatores, porque "[...] a compreensão que o indivíduo tem de sua língua não está orientada para a identificação de elementos normativos do discurso, mas para a apreciação de sua nova qualidade contextual" (BAKHTIN/VOLOCHÍNOV, 1988, p. 103).

Bakhtin observa que a concepção da linguística formal-sistemática promove um abismo entre as formas dos elementos constituintes da enunciação e as formas do todo em que ela se insere, pois seu estudo considera os aspectos formais imanentes da enunciação, deixando de fora da análise tudo o que pode denominarse "política externa" da enunciação. Limita-se a tomar, no máximo, a frase complexa.

De acordo com a visão bakhtiniana, as formas de uma enunciação completa só podem ser compreendidas e percebidas quando em relação com as demais enunciações de um domínio ideológico. Dessa maneira, por exemplo, as formas do texto literário só podem ser percebidas e apreendidas na relação com outras formas de enunciação completa desse âmbito de produção, o que aponta para a questão do gênero, ou seja, os gêneros literários não podem figurar como um monumento linguístico; se assim for feito, perde-se o acesso à literatura como um todo.

Esse ponto de vista é crucial tanto para o estudo quanto para o ensino/aprendizagem de língua e literatura. Embora o objetivismo abstrato possa produzir estudos legítimos no que diz respeito à análise linguística, é inegável que esses estudos não alcançam a essência da linguagem, uma vez que as implicações sociais/ideológicas/axiológicas da língua são preponderantes na produção de sentido e, portanto, sob a ótica de Bakhtin, não devem ser desconsiderados pelos estudos que são promovidos no âmbito da linguística.

Nesse contexto, consideramos o conceito de gênero discursivo primordial para essa discussão, podendo apontar para novas modalidades metodológicas que sejam mais significativas para o desenvolvimento da leitura/escrita. 
Partindo do princípio bakhtiniano de que os gêneros nos são dados como nos é dada a língua materna e que são introduzidos em nossa experiência e em nossa consciência conjuntamente sem que sua estreita correlação seja rompida, consideramos que os gêneros do discurso organizam nossa fala da mesma maneira que a organizam as formas gramaticais (sintáticas) e que desenvolvemos nossa linguagem verbal a partir do gênero. O pressuposto é de que nos processos interativos identificamos, antes de qualquer coisa, o gênero em questão.

De acordo, ainda, com essa análise, a língua não é transmitida e o indivíduo não a adquire, não a recebe pronta para ser usada. O que ocorre é um adentramento, um mergulho nas correntes verbais de comunicação que possibilita à consciência despertar, desenvolver-se e operar. Essa é a visão da língua enquanto constitutiva do sujeito que aponta para um estudo, uma pesquisa diferente da que se faz na tradição do objetivismo abstrato, uma vez que a atitude do objetivismo abstrato toma a língua como uma abstração, fora dos processos de comunicação verbal, da interação discursiva que comporta os fatores sócio-histórico-ideológicos. Há, nessa perspectiva, que considerar necessariamente o vínculo existente entre a língua e a vida, tendo em vista a historicidade do evento no estudo e na análise da língua(gem). Desse modo, há que se ter em vista necessariamente o gênero discursivo, pois o pressuposto é de que o homem organiza a realidade através da linguagem e nela se constitui (MEDVIEDEV, 2012). Nesse contexto, acreditamos que a tomada de consciência e a compreensão da realidade não ocorrem mediante a linguagem e suas formas no sentido linguístico do termo, mas são as formas do enunciado e não as formas da língua que desempenham um papel importantíssimo no conhecimento e na concepção da realidade. Não pensamos mediante palavras ou orações, e a corrente discursiva que nos atravessa não é uma mera sucessão de palavras e orações. Pensamos e compreendemos mediante unidades complexas que são os gêneros/enunciados. O gênero não pode ser compreendido como uma unidade do sistema da língua, suas formas não são formas sintáticas, mas comportam uma complexidade que demanda estudo e pesquisa.

Nessa perspectiva, caminha a concepção de gênero discursivo abordada pelo Círculo. Medviédev (2012), ao tratar o problema do gênero na construção artística, dialogando com os formalistas, afirma que o gênero é uma categoria que deve ser tomada como ponto de partida, pois ele comporta a totalidade da obra. Só se pode compreender a importância estrutural de cada elemento do enunciado concreto em 
relação ao gênero, tomando-o como uma realidade orgânica. Não há como atribuir uma significação estrutural autônoma aos elementos abstratos da língua.

Em relação ao acabamento estético ${ }^{1}$, o gênero é preponderante, uma vez que ele está na base do projeto discursivo. Isso significa que o gênero é o ponto de partida e não um elemento a mais na definição do enunciado. Nesse sentido, cada gênero é um modo especial de construir e dar acabamento e é capaz de abarcar tão somente determinados aspectos da realidade. Cada gênero possui determinados princípios de seleção, determinadas formas de visão e concepção da realidade, determinados graus na capacidade de abarcar e penetrar com profundidade na realidade e promover acabamento substancial na unidade temática.

Considerando o ensino/aprendizagem da leitura/escrita, tomar o projeto discursivo, necessariamente vinculado ao gênero, é imprescindível para a compreensão dos processos que regulam e orientam os elementos constitutivos da leitura/escrita. Bakhtin, na obra Questões de estilística e ensino, acerca das formas gramaticais em relação à estilística, afirma:

[..] o aluno aprende em quais condições uma oração subordinada adjetiva pode ser transformada em um particípio e quando tal mudança é impossível, além de tomar conhecimento da técnica gramatical dessa conversão. Entretanto, nem os professores nem o manual explicam ao aluno quando e para quê essa alteração é feita. Involuntariamente o aluno se pergunta: para que preciso saber fazer tal transformação, se não entendo o seu objetivo? (2013, p. 25).

Ao abordar o quando e o para quê das transformações, Bakhtin aponta necessariamente para o projeto discursivo que traz, em seu bojo, necessariamente atrelado, o gênero discursivo. A possível questão do aluno leva aos questionamentos feitos, há décadas, nas pesquisas acerca do ensino/aprendizagem dos conteúdos obsoletos e as metodologias arcaicas responsáveis, entre outros tantos fatores, pela desmotivação de alunos e professores com resultados pouco satisfatórios.

A escola, ao tratar da leitura/escrita apenas numa perspectiva formal, tendo em vista os sistemas de regras fonológicas, morfológicas, sintáticas, semânticas e seu léxico - como tradicionalmente tem se perpetuado na maioria das escolas, ainda que tantas pesquisas e documentos oficiais apontem em outra direção - apresenta

\footnotetext{
${ }^{1}$ Acabamento não tem a ver com finalização, mas como a obra é organizada em função da unidade temática é o tratamento estético.
} 
um ensino primordialmente prescritivo, focado nos aspectos formais e normativos, dando pouca ênfase, no que seria, do ponto de vista que se faz nos estudos bakhtinianos, mais profícuo, ao estudos dos gêneros discursivos centrados no contexto de interação discursiva. Fica evidente que o sentido de um enunciado concreto não está dado apenas em sua materialidade formal, mas aponta, mesmo vinculado a ela, para o contexto efetivo em que se dá a interação discursiva da qual resulta. E desconsiderar a realidade do enunciado concreto com todas as suas implicações será sempre fazer uma abordagem parcial, talvez artificial, da língua(gem).

Esse ensino fragmentado, desvinculado das condições de produção, segundo Bakhtin (2013), não favorece a apropriação efetiva da linguagem, uma vez que dificulta a construção do sentido e não ajuda na criação de uma linguagem própria, visto que apenas visa à análise da linguagem alheia dada pronta, estabelecida e descontextualizada, uma metodologia escolástica, medieval, calcada numa orientação monológica, na contramão do princípio dialógico inerente à linguagem.

Acreditamos que a maneira de promover, mais facilmente, a construção do sentido no que diz respeito ao ensino/aprendizagem da leitura/escrita - além da superação do dogmatismo monológico na abordagem do ensino/aprendizagem da língua - consiste em partir do gênero discursivo, levando a compreensão da arquitetônica que compreende esse conceito, sem perder de vista o projeto discursivo que o engendrou contendo todos os elementos que o constituem indissociavelmente.

Segundo Bakhtin, gênero comporta a totalidade do enunciado, que está na base da interação discursiva. Essa totalidade é preponderante para a construção dos sentidos e do desenvolvimento da competência linguística que compreende, necessariamente, um desenvolvimento do repertório de gêneros, pois, segundo Bakhtin e o Círculo, é através dos enunciados que a língua entra na vida e, sendo assim, os gêneros - forma típica relativamente estável do enunciado - possibilitam a interação discursiva, ou seja, "[a] vontade discursiva do falante se realiza antes de tudo na escolha de um certo gênero do discurso" (BAKHTIN, 2000, p. 282; grifos do autor).

A noção de gênero apresentada pelo Círculo bakhtiniano comporta uma arquitetônica que inclui a totalidade do enunciado materializado no ato discursivo. Essa totalidade comporta vários elementos indissociáveis, quais sejam: 
acabamento, conteúdo temático, unidade temática, forma composicional, estilo, intencionalidade, entonação expressiva, locutores (enunciador e enunciatário), bem como toda a dimensão extraverbal, as esferas de produção e circulação inerente aos fatores de sócio-histórico-ideológicos. Cada elemento faz parte necessariamente do enunciado sem uma hierarquia, isto é, todos são partes fundamentais, constroem a totalidade do enunciado/gênero. Obviamente são conceitos complexos que demandariam mais tempo e estudo para um esclarecimento satisfatório.

O conceito de gênero/enunciado na teoria bakhtiniana comporta todas as instâncias: linguística, enunciativa e discursiva. $\mathrm{Na}$ concepção do Círculo bakhtiniano, essas instâncias são indissociáveis no ato discursivo, que consiste no processo de atravessar o mundo e ser por ele atravessado. Conhecer, representar o real significa estar no mundo, dar sentido à realidade. Esse processo só é possível na linguagem e a linguagem, para Bakhtin, é um fenômeno social, é eminentemente dialógica, isto é, todo ato discursivo é sempre uma resposta. Desse ponto de vista, como foi explicitado até agora, não há como estudar genuinamente a linguagem tendo em vista apenas critérios linguísticos; há que se ter em vista a totalidade do ato discursivo que aponta necessariamente para uma realidade extralinguística imprescindível para a construção dos sentidos. E acrescentamos que o ensino/ aprendizagem que se pretenda mais significativo também não pode desconsiderar essa totalidade.

Desse modo, o ensino/aprendizagem de língua deve ter como ponto de partida o enunciado/gênero discursivo, uma vez que esse conceito se mostra, na concepção bakhtiniana, como a unidade central da comunicação verbal. A metodologia de ensino/aprendizagem, nessa perspectiva, não pode perder de vista essa realidade e considerar que, na prática, a teoria é outra, isto é, desconsiderar a essência da linguagem, fragmentando a língua, atendo-se apenas às formas estruturais e materiais, isolando-a da totalidade do ato discursivo.

Ao observarmos os manuais de Língua Portuguesa [Português: contexto, interlocução e sentido, v. 1, 2, 3 (2008)] adotados na rede estadual do Espírito Santo nos anos de 2012 a 2014, notamos que a metodologia, alem de expressar, como é esperado, a lógica conteudista, apresenta a fragmentação entre os conteúdos das normas gramaticais, a historiografia da literatura brasileira e a produção de texto escrito, o que torna a prática de sala de aula menos significativa do que poderia ser se a abordagem não fosse tão fragmentada. Os sumários dos três volumes do 
referido manual é dividido em três partes: 1- Literatura, constando os movimentos estéticos, a historiografia da literatura em Portugal e no Brasil; 2- Gramática, contendo os conceitos da gramática normativa, seguindo o modelo estruturalista, demonstrando os conceitos de morfologia, sintaxe, fonologia etc., separadamente e, finalmente, 3- Produção de texto, em que alguns gêneros discursivos são citados, tais como crônica, conto etc., sem, contudo, entrar na especificidade, no que vem a ser cada gênero. Os gêneros discursivos (conto, crônica, relatório, resumo, etc.) são mencionados em algumas seções dos manuais (2008) e nem chegam a ser enfocados como um conceito; são apenas apontados.

Essa abordagem fragmentada, tomando os conteúdos de gramática, literatura e leitura/produção de texto separadamente, como se um nada houvesse com o outro, mantem a tradição de ensino na antiga proposta sobre a qual discorremos na primeira parte desse trabalho (crítica de Bakhtin ao Obetivismo Abstrato), em que a língua é tomada em sua estrutura, desconsiderando as condições de produção, promovendo, como pode ser constatado, um distanciamento entre a língua(gem) dos alunos e a lingua(gem) proposta pelo livro.

É comum os alunos não terem nenhuma intimidade com o livro; muitos se recusam a recebê-lo e, quando o fazem, não o levam para a escola, esquecem em casa, perdem, etc. Em alguns depoimentos, eles afirmam não entender o livro, e que o livro fala outra língua e, portanto, é muito chato. Obviamente, o manual didático é um instrumento que, mesmo apresentando uma teoria fragmentada, pode atender a uma prática mais significativa nas mãos de um professor bem formado, se aliado a outros materiais didáticos. Entretanto, o que tem se observado é um uso solitário e precário do manual didático. Essa é uma questão complexa e constitui um desafio a ser equacionado tantos por pesquisadores da área quanto pelo corpo docente das diversas escolas públicas da educação básica.

A despeito de toda a problemática e desafio que hoje encontramos numa escola cujo modelo demonstra certa falência, uma vez que temos uma escola idealizada nos moldes da Escolástica (Idade Média), com professores formados também nessa tradição e alunos do século XXI que pouco se adéquam a esse desenho de ensino, estamos aqui apenas a abordar uma face dessa complexidade, que é a escola da educação básica atualmente. Ou seja, abordamos apenas a perspectiva de ensino/aprendizagem da disciplina de Língua Portuguesa e observamos, no que diz respeito ao gênero discursivo, a abordagem nos manuais 
didáticos (2008) da rede estadual, o que, como é sabido, não difere muito dos manuais de outras redes.

Certamente que um ensino/aprendizagem mais significativo e profícuo, como um todo, demandaria mudanças estruturais sérias e urgentes em todo sistema educacional, o que constitui um imenso desafio que não deve nem pode estar na responsabilidade de um segmento da sociedade; ao contrário, deve ser pensado por todos, sociedade civil, instituições privadas, governo e, sobretudo, pesquisadores que se debruçam sobre essa questão há anos sem serem ouvidos, tendo suas vozes abafadas pela lógica do mercado que se impõe e define as regras do funcionamento de escolas e universidades.

Entretanto, acreditamos que, no que diz respeito ao ensino de língua materna, ainda que seja um recorte desse todo, a proposta que ora apresentamos pode configurar como uma tentativa de promover um ensino/aprendizagem de língua materna mais significativo e mais eficiente. Obviamente, num sistema educacional ultrapassado as chances de lograr êxito são pequenas, mas não impossível. Porém, se aliada a essa abordagem pudéssemos contar com uma escola onde os alunos fossem protagonistas, sem executar uma educação bancária, repetindo padrões impostos a todos, no mesmo tempo/espaço, as possibilidades seriam muito melhores. Evidentemente, deve haver experiências inovadoras e exitosas que rompem com o modelo tradicional de escola sobre o qual estamos a discutir, porém acreditamos serem ainda experiências tímidas se comparadas com a grande massa da educação pública praticada no país e no estado de onde falo.

Como já mencionado, as interações discursivas se dão através dos gêneros. Considerando que cada vez mais as tecnologias fazem proliferar gêneros e subgêneros, exigindo um letramento cada vez mais amplo, uma competência de leitura/escrita mais sofisticada, justificamos que o ensino/aprendizagem de língua materna, ao contemplar o gênero discursivo, vincula necessariamente as condições de produção do gênero, uma vez que deve apresentar os fatores que determinam a configuração do gênero discursivo, quais sejam: a esfera de produção, forma composicional, enunciador, enunciatário, unidade temática, acabamento estético, intencionalidade do projeto discursivo, etc. Todos esses fatores devem ser esclarecidos na apresentação do gênero. Entretanto, não se pode correr o risco de transformar esses fatores em novos conteúdos, tornando a abordagem novamente fragmentada, levando os alunos a memorizarem nomenclatura, como ocorreu em 
algumas iniciativas de determinadas escolas. O ensino/aprendizagem a partir do gênero discursivo só faz sentido se estiver a serviço do desenvolvimento da leitura/escrita e, aqui, trata-se de múltiplas leituras, trazendo para o cotidiano da disciplina de língua materna uma gama variada de gêneros discursivos que fazem ou deveriam fazer parte da vida estudantil. Nesse sentido, o currículo da disciplina de língua materna da educação básica deve abrir espaço para os quadrinhos, reportagens de TV, vídeos, canções, revistas e jornais impressos e digitais, sites, blogs, etc., bem como os gêneros consagrados da literatura que, embora não tenham deixado de ocupar lugar no currículo, estão cada vez mais ausentes da vida estudantil, o que creditamos a toda complexidade e falência do modelo educacional em vigor. Enquanto o professor estiver com salas lotadas de alunos, com tempo restrito para planejamento e atendimento aos alunos, o ensino/aprendizagem de leitura/escrita tende a ficar empobrecido.

O que nos parece essencial na abordagem do gênero discursivo para o desenvolvimento da leitura/escrita é que a questão do sujeito e seu projeto discursivo devem estar na base da discussão e apresentação do gênero. Acreditamos que esse seja o ponto fulcral da aula de língua materna e constitui-se no pulo do gato para uma prática inovadora que se pretende mais significativa e eficiente.

É imprescindível que fique claro, entre todos os elementos constituintes do enunciado/concreto, que ele é a concretização de um projeto discursivo de um dado sujeito. Dessa maneira, consideramos que há mais possibilidade de se estabelecer mais facilmente a compreensão dos demais elementos do gênero como a esfera, o destinatário, o acabamento, a unidade temática, etc. Nessa questão é importante lembrar, como aventado, há muito, por outros pesquisadores sobre o ensino de língua (Geraldi, Bernardo, Fiorin, Brait) que a prática de produção de texto, normalmente fracassada pela metodologia escolar, haja vista os resultados das redações nas avaliações sistêmicas, deve-se ao fato de que o aluno nunca tem voz ativa. A escrita do educando, na escola, está sempre vinculada a um ensino prescritivo, isto é, eles devem escrever não para dizer o que pensam ou sentem, mas para provar o domínio das normas gramaticais que foram o foco da aula de língua portuguesa. Acreditamos que a leitura/escrita alheia ao projeto discursivo em questão quase sempre dificultará a construção do sentido e, consequentemente, dificultará o ensino/aprendizagem da leitura/escrita. Nesse contexto, afirma Brait 
(2013, p. 16): "De fato, o principal objetivo de quem ensina língua é levar o aluno a ler e escrever com autonomia, tornando-se sujeito dessas duas atividades interligadas para a constituição de sua constituição de cidadão".

$\mathrm{Na}$ proposta de trabalho na disciplina de Língua Portuguesa, a partir dos gêneros, é imprescindível considerar que o gênero/enunciado concreto possui uma arquitetônica com elementos que são necessariamente indissociáveis e que não se pode esquartejar o enunciado perdendo a sua totalidade. É importante considerar ainda que o projeto discursivo de cada gênero está intimamente ligado à esfera, forma composicional, intencionalidade, tema, acabamento, tom apreciativo, etc. e, sobretudo, que o enunciado concreto é a materialização realizada pelo sujeito enunciador, que ocupa um lugar social, atendendo a determinados interesses. Sem esse cuidado, cai-se novamente na fragmentação executada pelo ensino tradicional focado na estrutura, desvinculado das condições de produção, produzindo uma prática pouco, ou nada, significativa.

O gosto pela leitura/escrita como uma ação responsiva e autônoma parece não ocorrer facilmente através de um ensino que explora as características das formas composicionais dos gêneros ou expõe a nomenclatura gramatical da langue. O que nos parece que produz mais frutos é quando os alunos se apropriam de ações/atitudes inerentes à leitura/escrita através de debates, trocas de ideias, partilha dos pontos de vista, do tom apreciativo, ou seja, atitudes que permitem a revelação e o posicionamento do sujeito.

Ponderamos, assim, que, nessa direção, deve ser orientado o currículo da disciplina de Língua Portuguesa da educação básica. E, nesse caso, surge inevitavelmente a questão sobre quais gêneros devem ser priorizados. O critério de escolha deve estar vinculado ao projeto político pedagógico da instituição, e, consequentemente, vinculado ao projeto de sociedade que se quer construir/ estabelecer. Mas, a despeito do projeto que se quer, pode-se aventar que o currículo, de um modo geral, deve proporcionar o contato com uma gama diversificada de gêneros, contemplando os textos canônicos da literatura bem como propiciando ao aluno o contato e o domínio dos gêneros exigidos na sociedade atual, promovendo multiplicidade na leitura/escrita, ou seja, os multiletramentos.

Entretanto, voltamos a afirmar que não basta propor novas metodologias de ensino sem pensar na estrutura educacional como um todo, considerando que o modelo de escola tradicional que vigora em quase todas as escolas do estado do 
Espírito Santo segue o padrão em que a sala de aula se constitui de alunos ouvindo e professor falando. Ainda prevalece o esquema de aula expositiva, um desenho idealizado para funcionar num sistema autoritário, verticalizado. Acreditamos que toda a pesquisa e teoria dos últimos vinte anos (nada do que estamos a propor é inédito) no que diz respeito ao ensino/aprendizagem de língua materna não teve êxito por que as metodologias propostas não levaram em conta o restante da estrutura do sistema que inviabiliza uma prática diferenciada, a começar da arquitetura da escola tradicional, pensada a partir da cadeia e do hospício (FOUCAULT, 1987). No que diz respeito ao ensino de língua, sobretudo, o de língua materna, há que haver superação da escolástica, de um ensino verticalizado, monológico e dogmático, uma vez que a característica essencial da linguagem é o dialogismo e, portanto, um ensino/aprendizagem que se pretenda significativo deve seguir na direção do diálogo.

Na obra Marxismo e Filosofia da Linguagem, Bakhtin/Volochinov afirma que a abordagem da língua deve levar em conta, de maneira indissociável, os três níveis: discursivo, enunciativo e linguístico (1988, p.124). Consideramos que essa posição aponta necessariamente para o gênero discursivo, uma vez que é impossível fazer tal abordagem desconsiderando o gênero, pois, como já esclarecido na primeira parte desse trabalho, o gênero está na base do projeto discursivo. E novamente consideramos oportunas as palavras de Brait, quando assevera que a perspectiva bakhtiniana "É antes de tudo um conceito dialógico de linguagem que, assumido didaticamente pelo professor, coloca em movimento aspectos constitutivos da relação sujeito/linguagem, comunicação/expressividade, leitura/produção/autoria" (2013, p.17; grifos do autor)

Nessa direção, a aula de língua portuguesa deve estar centrada numa situação concreta de interação discursiva. Obviamente os níveis podem ser tratados separadamente, enfocando o que caracteriza cada um, o linguístico, o enunciativo e o discursivo. Entretanto, há que se ter em vista que todos os níveis estão imbricados servindo ao projeto discursivo materializado no gênero/enunciado concreto.

Essa metodologia, ainda que já bastante ventilada por alguns teóricos e estudiosos dessa questão, continua inédita nos manuais didáticos referentes ao ensino/aprendizagem de língua portuguesa da educação básica, de um modo geral. A coleção que serviu ao ensino médio da rede estadual do Espírito Santo, no triênio 2012, 2013 e 2014, passa longe dessa proposta. 
Como se pode observar no sumário da coleção, o manual repete o ensino tradicional, abordando separadamente o ensino de gramática, leitura, produção de texto e o ensino de Literatura. Não há sequer conexão entre esses elementos e muito menos no que diz respeito ao gênero discursivo, apenas mencionado como mera nomenclatura na seção de produção de texto, quando propõe a escrita de alguns gêneros, tais como, contos, crônicas, relatórios, etc.

\section{Considerações Finais}

Finalizamos, fazendo algumas considerações breves acerca de possíveis abordagens do gênero discursivo que podem caminhar na perspectiva do gênero como ponto de partida para o ensino/aprendizagem de língua, favorecendo a autonomia no processo de leitura/escrita, fazendo a ressalva de que dada a complexidade desse empreendimento, não pode ser fruto de apenas uma pesquisa, e demanda, além de tempo, a formação de uma equipe voltada para a questão, empenhada na proposição de uma metodologia, apontando práticas mais completas.

Nesse contexto, acreditamos que a lógica de funcionamento da aula deveria ser diferente do que caracteriza a tradição do ensino de língua: parte do conceito para a produção. A aula, na escola tradicional, direciona a leitura/escrita para o conteúdo a ser ministrado, e o papel do sujeito não importa. E nesse sentido, o ponto de partida não pode ser o conteúdo, o conceito, pois se assim for, sendo o conteúdo o gênero, ou outro qualquer, não faz muita diferença. $O$ que consideramos importante e necessário para um ensino/aprendizagem mais significativo é que haja um trabalho em que a voz do aluno tenha lugar e ele tenha o que dizer, em que a ação de leitura/escrita seja uma ação responsiva consciente de que estar no mundo implica dar respostas.

\section{Referências}

ABAURRE, Maria Luiza M. et alli. Português: contexto, interlocução e sentido. São Paulo: Moderna, 2008, v. 1, 2 e 3. 
BAKHTIN, M./VOLOCHINOV, V. Marxismo e filosofia da linguagem: problemas fundamentais do método sociológico na ciência da linguagem. Tradução de Michel Lahud e Yara Frateschi Vieira. São Paulo: Hucitec, 1988.

BAKHTIN, M. Questões de estilística no ensino da Língua. Tradução Sheila Grillo e Ekaterina V. Américo. São Paulo: Editora 34, 2013.

. Os Gêneros do discurso. In: BAKHTIN, Mikhail. Estética da criação verbal. 5. ed. Tradução Paulo Bezerra. São Paulo: Martins Fontes, 2010, p. 261-306.

BRAIT, B. Lições de gramática do professor Mikhail M. Bakhtin. In: BAKHTIN, M. Questões de estilística no ensino da língua. Tradução, posfácio e notas de Sheila Grilo e Ekaterina V. Américo. São Paulo: Editora 34, 2013.

FIORIN, José Luiz. Interdiscursividade e intertextualidade. In: BRAIT, Beth. Bakhtin: Outros conceitos-chave. São Paulo: Contexto, 2008. p. 161-193.

FOUCAULT, Michel. Vigiar e Punir: nascimento da prisão. Tradução Lígia M. Ponde Vassalo. Petrópolis: Vozes, 1987.

LIMA, S. M. M. O conceito de gênero e a concepção de linguagem presente nas Orientações Curriculares de Língua Portuguesa para o Ensino Médio. In: BERNARDO, S.; AUGUSTO, M. R. A.; VASCONCELLOS, Z. (Orgs). Linguagem: Teoria, Análise e Aplicações (6). Rio de Janeiro: Programa de Pós-graduação em Letras (UERJ), 2011, p. 151 a 158.. Disponível em: <http://www.pgletras.uerj.br/ linguistica/linguagem06.html>. Acesso em: 20 nov. 2012.

MEDIÉVEDEV, Pável Nikoláievitch. O método formal nos estudos literários: introdução crítica a uma poética sociológica. Tradução de Ekaterina V. Américo e Sheila C. Grillo. São Paulo: Contexto, 2012. 